Research Article

\title{
Prevalence of Malnutrition and its Impact on Academic Performance of School going Children from Rural Area of Rohtak, Haryana
}

\author{
Seema Verma', Neelam Kumar ${ }^{2}$, Shiba ${ }^{3}$, Priyanka Choudhary ${ }^{4}$, Komal Singhania ${ }^{5}$, \\ Mukesh Kumar ${ }^{6}$ \\ 1,5,6Resident, ${ }^{2}$ Professor, ${ }^{3,4}$ Senior Resident, Department of Community Medicine, PGIMS, Rohtak, Haryana, India. \\ DOI: https://doi.org/10.24321/2455.7048.201919
}

I $\quad \begin{array}{llll}\mathbf{N} & \mathbf{F} & \mathbf{O}\end{array}$

\section{Corresponding Author:}

Seema Verma, Department of Community Medicine, PGIMS, Rohtak, Haryana, India.

E-mail Id:

seema.verma426@gmail.com

Orcid Id:

https://orcid.org/0000-0001-5428-3470

How to cite this article:

Verma S, Kumar N, Shiba, Choudhary P, Singhania $\mathrm{K}$, Kumar M. Prevalence of Malnutrition and its Impact on Academic Performance of School going Children from Rural Area of Rohtak, Haryana. Epidem Int 2019; 4(4): 16-19.

Date of Submission: 2019-12-17

Date of Acceptance: 2020-01-23
$\begin{array}{llllllll}\mathbf{A} & \mathbf{B} & \mathbf{S} & \mathbf{T} & \mathbf{R} & \mathbf{A} & \mathbf{C} & \mathbf{T}\end{array}$

Background: Malnutrition is one of serious public health problem affecting children in developing countries like India. Adequate nutrition during childhood is vital for proper physical and mental development. The purpose of this study was to assess the association of malnutrition with scholastic performance of school going children of rural Rohtak.

Methods: This cross-sectional study was conducted among 392 school children of age 5 to 19 years of village Makrauli in Rohtak, Haryana, India. Malnutrition was assessed using anthropometric measurements and school records were used to analyse scholastic performance. Values of height, weight and BMI were recorded and converted into respective $Z$ scores using WHO ANTHRO PLUS software. Z scores were categorized into <-3SD, -2SD to -3SD, Normal and >2SD according to WHO 2007 Z score charts.

Result: A total of 392 children across 2 private schools and 1 government school were evaluated. In our study $27.5 \%$ children were found to be underweight. Stunting was present in 66 children (16.8\%). Wasting was found $23.7 \%$. Significant association between malnutrition and academic performance was observed.

Conclusion: Present study established a positive relationship between nutritional status and academic performance. Malnutrition is a major limiting factor for overall development of children.

Keywords: Malnutrition, Academic Performance, Undernutrition

\section{Introduction}

Malnutrition is a major public health problem in developing countries like India. India constitutes one third of the total malnourished children in the world. ${ }^{1}$ As per National Family Health Survey 4 (NFHS-4) data, the children under 5 years of age are underweight, stunted and wasted as 36\%, 38\% and $21 \%$, respectively. ${ }^{2}$ Adequate nutrition during childhood is vital for proper physical and mental development. Malnourished children are less likely to perform well in school and more likely to grow into malnourished adults. In India, government has taken steps to combat malnutrition among school children, by providing them 'mid-day meal'. 
But mid-day meal is provided only in the government schools but not in private schools. The present study was carried out to estimate the nutritional status of 5 to 19 year-old children in both private and government schools of randomly selected village from rural area of Rohtak (Haryana, India). Through this study, we intended to assess the nutritional status of both government and private school children and, at the time, assessed the relation of their nutritional status with academic performance.

\section{Methods}

This cross-sectional study was carried out in 5 to 19 yearold school-going children of village Makrauli, Rohtak, Haryana, India from October, 2018 to November, 2018. All the schools (both government and private) of village Makrauli were included in study. No school was excluded to prevent selection bias. Universal sampling technique was adopted for selection of schools and children to avoid selection bias. All the students of 5 to 19 years of age, who were present in schools at the time of visit and whose parents had given consent, were included in the study. Prior permission was taken from respective school principal. It was an observational study. However, all the ethical issues were taken into due consideration.

Height was taken using non-flexible metallic tape with minimum error of $1 \mathrm{~mm}$ and weight was taken using electronic digital weighing scale with minimum error of 100 $\mathrm{g}$ with standard precautions, same instruments were used throughout the study. Data was collected using pre-tested, pre-designed, semi-structured questionnaire (Table 1).

Table I.Proforma for data collection

\begin{tabular}{|c|}
\hline Name of school \\
\hline Date \\
\hline Name of student \\
\hline Age \& Sex \\
\hline Present class \\
\hline Last class Score as percentage \\
\hline Weight \\
\hline Height \\
\hline
\end{tabular}

Values of height, weight and BMI were recorded and converted into respective $Z$ scores using WHO ANTHRO PLUS software. Z scores were categorized into <-3SD, -2SD to -3SD, Normal and >2SD according to WHO 2007 Z score charts.

The health indicators used on the basis of Z score were:

Underweight: Children with weight for age Z score below 2 SD from the median of the reference population were considered to be underweight for their age.
Stunting: Children with height-for-age z-scores below 2 SD from the median of the reference population are considered short for their age or stunted.

Wasting: Children with BMI-for-age z-scores below 2 SD from the median of the reference population were considered thin, those with Z scores above 1 SD from the median of the reference population were considered overweight and while those with Z scores above 2 SD from the median of the reference population were considered obese.

Weight for Age Z (WAZ) score were taken only up to 10 years while Height for Age Z (HAZ) score and Body Mass Index for age Z (BMIZ) score were taken for all 5 to 19 years old children.

Academic performance was assessed using compiled report card available with respective class teachers. Overall scores were categorized into good $(>70 \%)$ and poor $(\leq 70 \%)$.

Collected data were coded appropriately, entered into MS Excel sheet and analyzed using SPPS 20.0 version. Chisquare test was used for statistical analysis considering $p$ value $<0.05$ as significant.

\section{Result}

In our study, 215 (54.85\%) were males and 177 (45.15\%) were females. The nutritional status of students has been described in Table 2.

The prevalence of malnutrition observed is shown in Table 3.

The malnutrition of children was more in government school as compared to private schools (Figure 1).

The nutritional status was significantly associated with academic performance as depicted in Table 4.

Table 2.Nutritional status of students

\begin{tabular}{|c|c|c|c|c|c|}
\hline \multicolumn{7}{|c|}{$\begin{array}{c}\text { Nutritional status of } \\
\text { students }\end{array}$} \\
\hline $\begin{array}{c}\text { Z } \\
\text { Scores }\end{array}$ & >2 SD & N & $-\mathbf{2}$ to - 3 SD & <-3 SD & Total \\
\hline WAZ $^{*}$ & 3 & 192 & 65 & 9 & 269 \\
\hline HAZ $^{* *}$ & 0 & 326 & 53 & 13 & 392 \\
\hline BMIZ $^{* *}$ & 2 & 297 & 82 & 11 & 392 \\
\hline
\end{tabular}

*WAZ, weight for age $Z$ score; ${ }^{* *} \mathrm{HAZ}$, height for age $Z$ score; ${ }^{* * * B M I Z,}$ body mass index for age $\mathrm{Z}$ score; $\mathrm{N}$, normal

Table 3.Prevalence of malnutrition

\begin{tabular}{|c|c|c|}
\hline Category & $\begin{array}{c}\text { Number of } \\
\text { students }\end{array}$ & Percentage \\
\hline Under wt & 74 & $27.5 \%$ \\
\hline Stunting & 66 & $16.8 \%$ \\
\hline Wasted & 93 & $23.7 \%$ \\
\hline
\end{tabular}




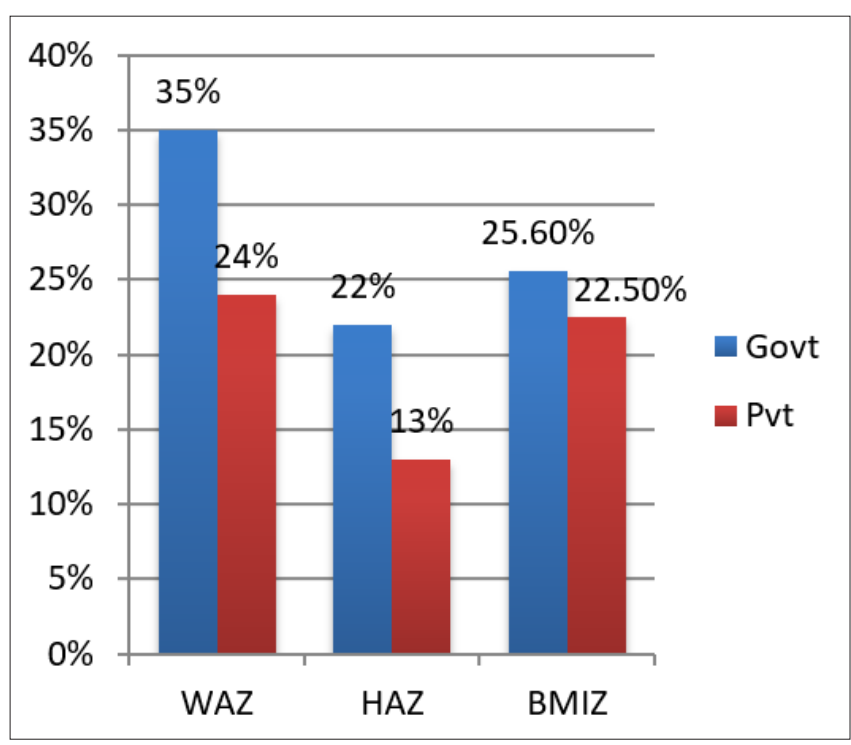

Figure I.Comparison of malnutrition between government and private schools

Table 4.Impact of malnutrition scholastic performance

\begin{tabular}{|c|c|c|c|c|c|}
\hline \multicolumn{6}{|c|}{ Impact of under nutrition on scholastic performance } \\
\hline & & Good & Poor & Total & $X^{2}$, df, p-value \\
\hline \multirow{2}{*}{$\mathrm{Wt}$} & Normal & 144 & 51 & 195 & \multirow{2}{*}{$4.36,1.0 .036$} \\
\hline & Under wt & 45 & 29 & 74 & \\
\hline \multirow{2}{*}{$\mathrm{Ht}$} & Normal & 237 & 89 & 326 & \multirow{2}{*}{$\begin{array}{c}11.54,1 \\
0.0006\end{array}$} \\
\hline & Stunting & 34 & 32 & 66 & \\
\hline \multirow{3}{*}{ BMI } & Over wt & 17 & 7 & 24 & \multirow{3}{*}{$10.51,2,0.005$} \\
\hline & Normal & 203 & 72 & 275 & \\
\hline & Wasted & 52 & 41 & 93 & \\
\hline
\end{tabular}

\section{Discussion}

The prevalence of malnutrition and its determinants were assessed in our present cross-sectional study. In our study $27.5 \%$ children were found to be underweight, using WHO 2007 standards. These results are comparable to the studies done by Agarwal et al. and Singh et al. which reported prevalence as $29 \%$ and $28.9 \%$ respectively. ${ }^{3,4}$ A study conducted by Bhoite et al. among rural children revealed higher prevalence of underweight (64\%). ${ }^{5}$ On the other hand, Rashmi et al. revealed lower prevalence rate (20\%). ${ }^{6}$

Stunting was present in 66 children, giving prevalence of $16.8 \%$. The results are comparable to studies by Rashmi et al., Agarwal et al. and Singh et al., which reported prevalence of $7 \%, 12 \%$ and $21.8 \%$, while a higher prevalence was reported by Clinical, Anthropometry and Biochemistry (CAB Uttar Pradesh) as 62\%. . $3,4,7^{-1}$

In the present study, the wasting was found to be $23.7 \%$ which was comparable to the study by Agarwal et al., which reported prevalence as $22 \% .{ }^{3}$ While the study by Rashmi et al. reported prevalence $34 \%{ }^{6}$

Prevalence of obesity in our study was $1.1 \%$ which is comparable to the studies done by Rashmi et al. (1\%) and Agarwal et al. (2\%). 6,3

Weight for age, height for age and BMI for age were compared with academic performance. It was found to be statistically significant $(p<0.05)$ and the results were comparable to findings by Rashmi. ${ }^{6}$

\section{Conclusion}

Present study established a positive relationship between nutritional status and academic performance. Malnutrition is a major limiting factor for overall development of children. In today's competitive world, where there is almost no scope for an average child, poor academic performances due to malnutrition can snatch away bright and beautiful future from children.

\section{Recommendation}

Our study recommends that regular health check-ups should be conducted at schools involving school authorities and doctors. All teachers and parents should be given health and nutritional education sessions by the health experts by conducting seminars or interactive health talks to enforce healthy eating habits among children. Parents should be informed about the health status of their children by class teachers during parent teacher meetings and appropriate measures should be taken to improve the lunch pack. National supplementation policy should also include private schools. More detailed studies are needed to determine the factors affecting diet of children apart from Mid-Day Meal.

\section{Limitation}

Academic performance is affected not just by nutrition, but also by other factors like social environment, study environment, hereditary factors, and the like but our study focused on nutritional component only.

\section{Conflict of Interest: None}

\section{References}

1. Health across life span, WHO, 1998 (Internet). Available from: http://www.who.int/whr/1998/en/whr98_ch3. pdf?ua=1 [Last accessed Dec 12, 2018].

2. National Family Health Survey 4, India Fact Sheet 201516, International Institute for Population Sciences, Mumbai. Available from: http://rchiips.org/nfhs/pdf/ NFHS4/India.pdf [Last accessed Dec 12, 2018].

3. Agarwal A, Jain S, Garg SK, Chopra H, Bano T. Prevalence of malnutrition and its impact on scholastic performance among 8-12 year children from 2 schools of urban Meerut. J Med Allied Sci 20218; 8(1): 3-6. Available from: http://jmas.in/sites/default/ 
files/articles/Prevalence\%20of\%20malnutrition\%20 and $\% 20$ its $\% 20 \mathrm{impact} \% 20$ on\%20scholastic\%20 performance\%20among\%208\%E2\%80\%9312\%20 year\%20children\%20from\%202\%20schools\%20of\%20 urban\%20Meerut.htm [Google Scholar/ ResearchGate].

4. Singh SP. Malnutrition among primary school children in Hyderabad, Andhra Pradesh, India. International Journal of Technical Research and Applications 2014; 2(1): 36-39. Available from: https://www. ijtra.com/view/malnutrition-among-primary-schoolchildren-in-hyderabad-andhra-pradesh-india. pdf?paper=malnutrition-among-primary-schoolchildren-in-hyderabad-andhra-pradesh-india.pdf [Google Scholar].

5. Bhoite R, lyer UM. Magnitude of malnutrition and iron defi-ciency anemia among rural school children: An appraisal. Asian Journal of Experimental Biological Sciences 2011; 2(2): 354-361. Available from: https:// www.ajebs.com/vol6/29.pdf.

6. Rashmi MR, Shweta BM, Fathima FN, Agrawal T, Shah M, Sequeira R. Prevalence of malnutrition and relationship with scholastic performance among primary and secondary school children in two select private schools in Bangalore Rural District (India). Indian J Community Med 2015; 40(2): 97-102. Available from: http://www.ijcm.org.in/article.asp?issn=0970-0218;ye ar=2015; volume=40;issue=2; spage=97; epage=102; au last=Rashmi [PubMed/ Google Scholar]

7. Clinical, Anthropometric and Biochemistry Fact Sheet, Uttar Pradesh, 2014, Census of India, 2014. (Internet). Available from: http://www.censusindia.gov. in/2011census/hh-series/HH-2/Uttar\%20Pradesh\%20 CAB\%20Factsheet\%202014.pdf. 